\title{
Pengaruh hubungan antar manusia dan lingkungan kerja terhadap etos kerja karyawan pada dealer sepeda motor honda armada tunas jaya palangka raya
}

\author{
Risnawati $^{1)}$,Agau Lenin ${ }^{2)}$,Hansly Tunjang ${ }^{3)}$ \\ Fakultas Ekonomi dan Bisnis Universitas Palangka Raya, Indonesia
}

\begin{abstract}
Abstrak
Tujuan, - Penelitian ini bertujuan untuk mengetahui bagaimana pengaruh hubungan antar manusia dan lingkungan kerja terhadap etos kerja karyawan Pada Dealer Sepeda Motor Honda Armada Tunas Jaya Palangka Raya.

Desain/Methodologi/Pendekatan - Metode penelitian yang digunakan dalam penelitian ini adalah metode deskriptif kuantitatif. Populasi dalam penelitian ini adalah seluruh karyawan Dealer Sepeda Motor Honda Armada Tunas Jaya Palangka Raya yang berjumlah 30 orang dengan teknik sensus. Temuan penelitian - Hasil penelitian menunjukkan bahwa hubungan antar manusia berpengaruh positif dan signifikan terhadap etos kerja karyawan, lingkungan kerja berpengaruh positif dan signifikan terhadap etos kerja karyawan dan secara simultan hubungan antar manusia dan lingkungan kerja bepengaruh positif dan signifikan terhadap etos kerja karyawan.
\end{abstract}

Kata kunci: Hubungan Antar Manusia, Lingkungan Kerja, Etos Kerja Karyawan.

Jenis artikel: Artikel penelitian

\section{The influence of human relations and the work environment on employee work ethic at honda motorcycle dealer armada tunas jaya palangka raya}

\begin{abstract}
Purpose, - This study aims to determine how the influence of relationships between humans and the work environment on the work ethic of employees at Honda Motorcycle Dealer Armada Tunas Jaya, Palangka Raya.

Design/methodology/approach - The research method used in this research is descriptive quantitative method. The population in this study were all employees of the Honda motorcycle dealership Armada Tunas Jaya Palangka Raya, totaling 30 people using the census technique.

Findings - he results showed that the relationship between humans had a positive and significant effect on the work ethic of employees, the work environment had a positive and significant effect on the work ethic of employees and simultaneously the relationship between humans and the work environment had a positive and significant impact on the work ethic of employees.
\end{abstract}

Keywords: Human Relations, Work Environment, Employee Work Ethic.

Paper type: Research Paper 


\section{Pendahuluan}

Pada perkembangan zaman yang modern ini, banyak perusahaan berdiri untuk bersaing di pasar nasional maupun internasional. Setiap perusahaan tersebut harus memiliki strategi untuk memajukan perusahaan dan siap bersaing di pasar global. Suatu persaingan yang begitu ketat dalam mendorong organisasi untuk memperbaiki kualitas usaha untuk mencapai tujuan organisasi, yaitu mencapai laba sebesar-besarnya. Untuk mencapai laba tersebut, setiap perusahaan memerlukan strategi-strategi yang harus ditempuh salah satunya adalah kualitas Sumber Daya Manusia yang mampu bekerja sama (Saputro, 2017).

Etos kerja merupakan sikap, pandangan, kebiasaan, ciri-ciri atau sifat mengenai cara bekerja yang dimiliki seorang karyawan. Jika karyawan mempunyai etos kerja yang tinggi, rutinitas kerja tidak akan membuat bosan, bahkan mampu meningkatkan prestasi kerjanya. Hal yang mendasari etos kerja tinggi yaitu keinginan dan kesadaran karyawan untuk menjunjung tinggi kualitas pekerjaan (Dodi, 2013).

Adapun beberapa faktor yang mempengaruhi etos kerja yaitu hubungan antar manusia dan lingkungan kerja karyawan. Adanya hubungan antar manusia yang baik, perusahaan dapat mencapai tujuan dikarenakan terdapat aktivitas dari karyawan atau orang-orang yang berada dalam perusahaan tersebut (Susanti, 2014).

Human relation merupakan hubungan atau interaksi dan komunikasi antara satu karyawan dengan karyawan yang lain, baik dalam situasi kerja ataupun diluar lingkungan kerja (Susanti, 2014).

Lingkungan kerja merupakan salah satu faktor dari fungsi Manajemen Sumber Daya Manusia, tepatnya fungsi perencanaan. Fungsi perencanaan berhubungan langsung dengan pegawai yang bekerja pada lingkungan organisasi. Dengan demikian lingkungan kerja dalam suatu organisasi akan berpengaruh kepada semua kegiatan organisasi (Lubis, 2015).

Berdasarkan hasil observasi awal peneliti, hubungan antar sesama karyawan ini masih rendah. Hal ini dapat dilihat dari masih ada karyawan yang mementingkan dirinya sendiri tanpa mementingkan suatu organisasi, mementingkan dirinya sendiri yang di maksud adalah kurangnya terjalin kerjasama antar sesama karyawan dan komunikasi yang kurang lancar seperti kurang sosialisasi untuk membantu karyawan yang membutuhkan pertolongannya, dengan tindakan karyawan tersebut maka etos kerja seorang karyawan kurang baik dan akan berdampak pada hasil kinerja karyawan.

Permasalah yang terjadi bukan hanya hubungan antar manusia tetapi juga kondisi lingkungan kerja karyawan yang kurang baik karena ruangan tempat bekerja yang kurang nyaman seperti kurangnya pemberian warna didalam ruangan, kurangnya fasilitas bangunan seperti tidak tersedianya tempat parkir, dengan kondisi kerja seperti ini maka akan membuat karyawan merasa jenuh ketika berada ditempat kerja, sehingga pekerjaan yang diberikan kepadanya tidak sesesuai pada target yang telah ditentukan.

Etos kerja karyawan yang baik adalah bagaimana segala macam pekerjaan yang diharapakan oleh perusahaan dapat dilakukan dengan baik, dan dengan hasil yang memuaskan. Etos kerja muncul disebabkan oleh beberapa faktor, bisa dari kemampuan karyawan itu sendiri atau bisa dari lingkungan pekerjaan. Kemampuan karyawan sendiri bisa dari bakat sejak lahir, namun Sebagian besar etos kerja timbul akibat lingkungan, rekan kerja, bahkan dari suasana kerja, peran dari perusahaanlah yang membantu tumbuhnya etos kerja karyawan. 


\section{Kajian Pustaka}

Menurut Hasibuan (2013:137), hubungan antar manusia (human relation) adalah hubungan kemanusiaan yang harmonis, tercipta atas kesadaran dan kesediaan melebur keinginan individu demi terpadunya kepentingan bersama, tujuanya adalah menghasilkan integrasi yang cukup kukuh, mendorong kerja sama yang produktif dan kreatif untuk mencapai sasaran bersama. Hubungan antar manusia (human relation) merupakan hubungan manusiawi yang selalu dibutuhkan oleh karyawan, dimana fungsinya sebagai makhluk pribadi dan makhluk sosial, kebutuhan akan orang lain untuk bekerjasama dalam mencapai tujuan hidupnya. Hubungan yang harmonis akan membuat suasana kerja yang menyenangkan dan hal ini akan mempengaruhi semangat karyawan dalam menjalankan segala pekerjaannya (Saputro, 2017).

Menurut Josephine (2017) lingkungan kerja adalah keseluruhan hubungan yang terjadi dengan karyawan ditempat kerja. Segala sesuatu yang berada ditempat kerja merupakan lingkungan kerja. Karyawan berada didalam sebuah lingkungan kerja ketika karyawan melakukan aktivitas pekerjaan, dan segala bentuk hubungan yang melibatkan karyawan tersebut termasuk dari lingkungan kerja. Lingkungan kerja merupakan suatu posisi dan keadaan dimana karyawan tersebut bekerja. Lingkungan kerja bagi karyawan akan memiliki pengaruh yang tidak kecil terhadap jalannya operasional suatu perusahaan.

Menurut Samosir (2016) etos kerja merupakan seperangkat sikap atau pandangan mendasar yang dipegang karyawan untuk menilai bekerja sebagai suatu hal yang positif bagi peningkatan kualitas kehidupan, sehingga mempengaruhi perilaku kerjanya dalam organisasi. Adapun Indikator etos kerja menurut (Wijayanti, 2017)

1. Penilain kerja

2. Pandangan kerja

3. Aktivitas

4. Ketekunan

5. Ibadah

Berdasarkan kajian tentang pengaruh hubungan antar manusia dan lingkungan kerja terhadap etos kerja karyawan, maka kerangka pemikiran dalam penelitian ini dapat digambarkan sebagai berikut:

Gambar 1. Kerangka Pemikiran

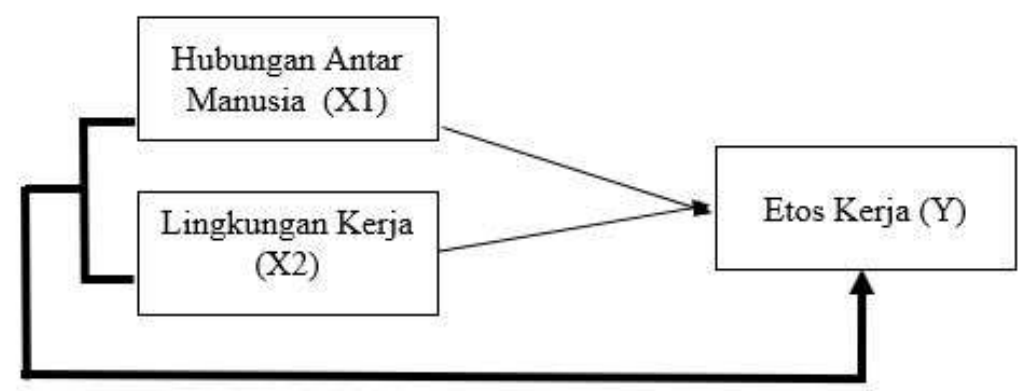

\section{Metode Penelitian}

Penelitian ini berlokasi di Dealer Sepeda Motor Honda Armada Tunas Jaya Palangka Raya yang terletak di jalan G. Obos No.68 ABC, Menteng, Jekan Raya Palangka Raya. Dengan jumlah responden sebanyak 30 orang dengan menggunakan teknis sampling jenuh 
atau sensus. Metode yang digunakan dalam penelitian ini menggunakan metode deskriptif kuantitatif. Analisis yang digunakan untuk mendapatkan gambaran dari data yang telah terkumpul berdasarkan jawaban responden melalui item kuesioner adalah analisis Regresi Linear Berganda dengan rumus sebagai berikut.

Persamaan : $\mathrm{Y}=\mathrm{a}+\beta 1 \mathrm{X} 1+\beta 2 \mathrm{X} 2+\mathrm{e}$

Keterangan:

Y : Etos Kerja Karyawan

X1: Hubungan Antar Manusia

$\mathrm{X} 2$ : Lingkungan Kerja

a : Konstanta

$\beta$ : koefisien estimate

e : Standar Error

\section{Hasil dan pembahasan}

Persamaan Regresi Linear Berganda

\begin{tabular}{|c|c|c|c|c|c|c|c|}
\hline \multirow[t]{4}{*}{ 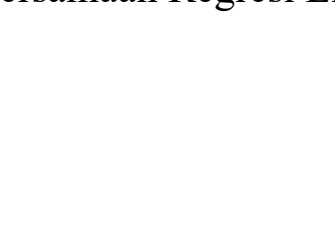 } & \multirow{3}{*}{ Model } & \multicolumn{6}{|c|}{ Coefficients $^{\mathrm{a}}$} \\
\hline & & & \multicolumn{2}{|c|}{$\begin{array}{l}\text { Unstandardized } \\
\text { Coefficients }\end{array}$} & \multirow{2}{*}{$\begin{array}{c}\begin{array}{c}\text { Standardized } \\
\text { Coefficients }\end{array} \\
\text { Beta }\end{array}$} & \multirow[t]{2}{*}{$\mathrm{t}$} & \multirow[t]{2}{*}{ Sig. } \\
\hline & & & $\mathrm{B}$ & Std. Error & & & \\
\hline & & (Constant) & -7.853 & 2.315 & & -3.391 & .002 \\
\hline & 1 & TOTALX1 & .335 & .077 & .498 & 4.367 & .000 \\
\hline \multirow{2}{*}{$\begin{array}{l}\text { Tabel } 1 \text {. Hasil Analisis } \\
\text { regresi Linear }\end{array}$} & & TOTALX2 & .483 & .113 & .486 & 4.267 & .000 \\
\hline & Sumb & S 21 & & & & & \\
\hline
\end{tabular}

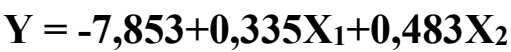

Berdasarkan hasil persamaan regresi linier berganda di atas maka dapat di interprestasikan sebagai berikut:

1. Nilai a $=-7,853$ maka jika nilai hubungan antar manusia $\left(X_{1}\right)$ dan lingkungan kerja $\left(X_{2}\right)$ tidak berpengaruh maka nilai constanta, etos kerja (Y) akan turun sebesar -7.853.

2. Koefisien regresi hubungan antar manusia menunjukan nilai sebesar 0,335

Artinya apabila variabel hubungan antar manusia $\left(\mathrm{X}_{1}\right)$ naik sebesar 1 tingkat maka etos kerja (Y) akan naik sebesar 0,335 atau 33,5\%

3. Koefisien regresi lingkungan kerja menunjukan nilai sebesar 0,483

Artinya apabila variabel lingkungan kerja $\left(\mathrm{X}_{2}\right)$ naik sebesar 1 tingkat maka etos kerja $(\mathrm{Y})$ akan naik sebesar 0,483 atau $48,3 \%$

Tabel 2. Hasil Uji t

\begin{tabular}{|c|c|c|c|c|c|}
\hline \multicolumn{6}{|c|}{ Coefficients $^{\mathrm{a}}$} \\
\hline \multirow[t]{2}{*}{ Model } & \multicolumn{2}{|c|}{$\begin{array}{c}\text { Unstandardized } \\
\text { Coefficients }\end{array}$} & \multirow{2}{*}{$\begin{array}{c}\text { Standardized } \\
\text { Coefficients } \\
\text { Beta } \\
\end{array}$} & \multirow[t]{2}{*}{$\mathrm{t}$} & \multirow[t]{2}{*}{ Sig. } \\
\hline & B & Std. Error & & & \\
\hline (Constant) & -7.853 & 2.315 & & -3.391 & .002 \\
\hline TOTAL (X1) & .335 & .077 & .498 & 4.367 & .000 \\
\hline TOTAL (X2) & .483 & .113 & .486 & 4.267 & .000 \\
\hline
\end{tabular}


Berdasarkan hasil uji secara parsial antara variabel hubungan antar manusia $\left(\mathrm{X}_{1}\right)$ terhadap etos kerja (Y) menunjukkan nilai thitung 4,367 > ttabel sebesar 1,703. dan signifikansi 0,000 $<0,05$ maka dapat disimpulkan bahwa Ho ditolak dan Ha diterima. Artinya variabel hubungan antar manusia $\left(\mathrm{X}_{1}\right)$ berpengaruh positif terhadap etos kerja $(\mathrm{Y})$.

Berdasarkan hasil uji secara parsial antara variabel lingkungan kerja $\left(\mathrm{X}_{2}\right)$ terhadap etos kerja (Y) menunjukkan nilai thitung 4,267 > ttabel sebesar 1,703 dan signifikansi 0,000< 0,05 maka dapat disimpulkan bahwa Ho ditolak dan Ha diterima. Artinya variabel lingkungan kerja $\left(\mathrm{X}_{2}\right)$ berpengaruh positif terhadap etos kerja $(\mathrm{Y})$.

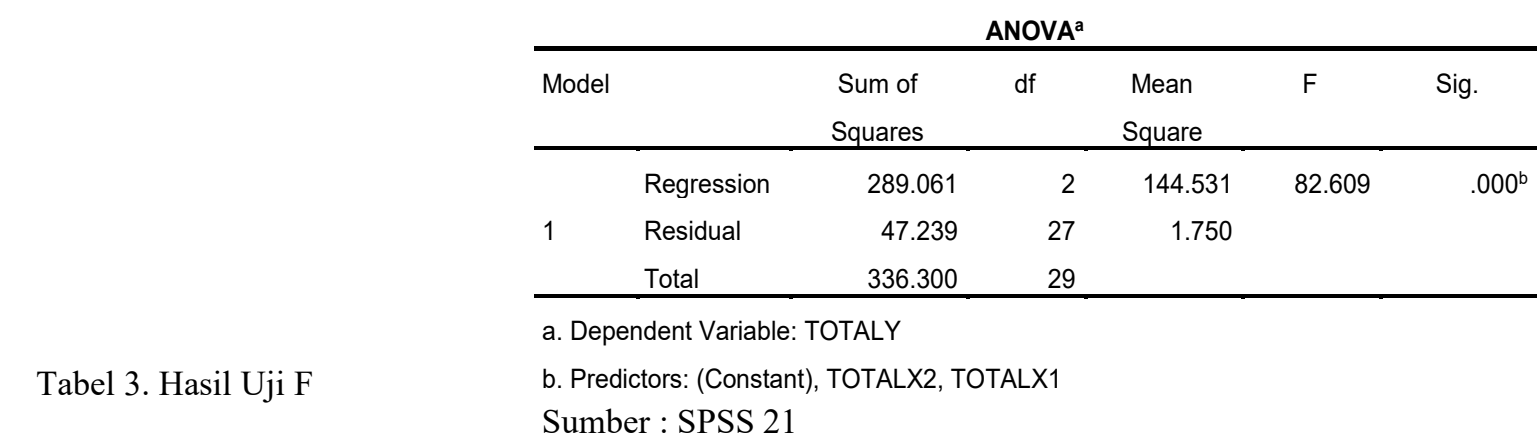

Berdasarkan hasil uji secara simultan antara variabel hubungan antar manusia $\left(\mathrm{X}_{1}\right)$ dan lingkungan kerja $\left(\mathrm{X}_{2}\right)$ terhadap etos kerja $(\mathrm{Y})$ menunjukkan nilai Fhitung 82,609 $>$ Ftabel sebesar 3,354 dan signifikansi 0,000 <0,05 maka dapat disimpulkan bahwa Ho ditolak dan Ha diterima. Artinya variabel hubungan antar manusia $\left(\mathrm{X}_{1}\right)$ dan lingkungan kerja $\left(\mathrm{X}_{2}\right)$ berpengaruh positif secara simultan terhadap etos kerja (Y).

\begin{tabular}{llccr}
\multicolumn{4}{c}{ Model Summary } \\
\hline Model & $\mathrm{R}$ & R Square & $\begin{array}{c}\text { Adjusted R } \\
\text { Square }\end{array}$ & $\begin{array}{c}\text { Std. Error of the } \\
\text { Estimate }\end{array}$ \\
\hline 1 & $.927^{\mathrm{a}}$ & .860 & .849 & 1.323 \\
\hline a. Predictors: (Constant), TOTALX2, TOTALX1 & & \\
b. Dependent Variable: TOTALY & & \\
Sumber : SPSS 21
\end{tabular}

Berdasarkan Tabel di atas hasil output SPSS versi 21 for Windows pada model summary di atas, diketahui besarnya angka koefisien determinasi korelasi $\left(\mathrm{R}^{2}\right)$ adalah sebesar 0,860 atau sama dengan $86,0 \%$. Angka tersebut mengandung arti bahwa kemampuan hubungan antar manusia $\left(\mathrm{X}_{1}\right)$ dan lingkungan kerja $\left(\mathrm{X}_{2}\right)$ menjelaskan etos kerja $(\mathrm{Y})$ sebesar 0,860 atau sama dengan $86,0 \%$ sisanya $(100 \%-86,0 \%=14,0 \%)$ tidak dimasukan dalam persamaan ini.

\section{Kesimpulan}

Setelah peneliti melakukan analisis mengenai pengaruh hubungan antar manusia dan lingkungan kerja tehadap etos kerja karyawan Pada Dealer Sepeda Motor Honda Armada Tunas Jaya Palangka Raya, maka penulis menyimpulkan bahwa: hubungan antar manusia $\left(\mathrm{X}_{1}\right)$ berpengaruh positif dan signifikan terhadap etos kerja karyawan $(\mathrm{Y})$, lingkungan kerja $\left(\mathrm{X}_{2}\right)$ berpengaruh positif dan signifikan terhadap etos kerja karyawan $(\mathrm{Y})$, hubungan antar 
manusia $\left(\mathrm{X}_{1}\right)$ dan lingkungan kerja $\left(\mathrm{X}_{2}\right)$ berpengaruh secara simultan terhadap etos kerja karyawan(Y).

Hasil penelitian yang telah dilakukan, maka peneliti memberikan saran sebagai berikut: Bagi pimpinan Dealer Sepeda Motor Honda Armada Tunas Jaya Palangka Raya, agar dapat selalu memperhatikan variabel hubungan antar manusia dan lingkungan kerja dalam rangka meningkatkan etos kerja karyawan. Bagi peneliti selanjutnya, penulis menyarankan agar dapat menambah variabel lain yang dapat memberikan kontribusi terhadap etos kerja karyawan. Selain itu dapat menggunakan metode lain dalam penelitian hubungan antar manusia dan lingkungan kerja terhadap etos kerja. Apabila peneliti selanjutnya ingin melakukan penelitian lebih lanjut mengenai hubungan antar manusia dan lingkungan kerja diharapkan peneliti dapat menambah sampel yang lebih banyak lagi demi keakuratan data dan juga untuk dapat melihat perubahan perilaku responden dari waktu ke waktu.

\section{Daftar Pustaka}

Choiriyah., \& Suhendar, Dendi. (2013). Pengaruh Motivasi dan Kompetensi Serta Lingkungan Kerja Terhadap Kinerja Tutor Pendidikan Kesetaraan Kelompok Belajar UPTD. SKB. Jurnal Orasi Bisnis.

Dodi, Ramli., Yunus, Mukhlis., \& Amri. (2013). Pengaruh Iklim Organisasi, Etos Kerja dan Disiplin Terhadap Kinerja Karyawan Serta Dampaknya Pada Kinerja PT. Arun NGL Lhokseumawe Aceh. Jurnal Manajemen. Vol.2, No.1.

Ghozali, Imam. (2013). Aplikasi Analisis Multivariate dengan Program IBM SPSS 21 Update PLS Regresi. Semarang: Universitas Diponegoro.

Ghozali Imam. (2018). Aplikasi Analisis Multivariate Dengan Program IBM SPSS 25. Edisi Kesembilan. Badan Penerbit Universitas Diponegoro, Semarang.

Hasibuan SP. Malayu. (2013). Manajemen Sumber Daya Manusia. Jakarta: PT. Bumi Aksara. Josephine, Audrey., \& Harjanti, Dhyah. (2017). Pengaruh Lingkungan Kerja Terhadap Kinerja Karyawan Pada Bagian Produksi Melalui Motivasi Kerja Sebagai Variabel Intervening Pada PT. Trio Corporate Plastic (Tricopla). Jurnal AGORA. Vol.5, No.3.

Lubis, Aswadi. (2015). Lingkungan Kerja yang Kondusif dan Faktor-faktor yang Mempengaruhinya. Vol.3, No.1.

Nuryasin, Ilham., Al-Musadieq, Mochammad., \& Ruhana, Ika. (2016). Pengaruh Lingkungan Kerja dan Motivasi Kerja Terhadap Kinerja Karyawan. Jurnal Administrasi Bisnis. Vol.41, No.1.

Rahmawanti, Nela, Pima., Swasto, Bambang., \& Prasetya, Arik. (2014). Pengaruh Lingkungan Kerja Terhadap Kinerja Karyawan. Jurnal Administrasi Bisnis. Vol.8, No.2.

Saputro, Galih, Adi., \& Fathoni, Azis. (2017). Analisis Pengaruh (Human Relation/ Hubungan Antar Manusia) dan Kondisi Fisik Lingkungan Kerja Terhadap Etos Kerja dan Kinerja Karyawan PT. Karunia Adijaya Mandiri Semarang.

Samosir Remalia. (2016). Pengaruh Kemampuan Intelektual dan Etos Kerja Terhadap Kinerja Pegawai Pada Kantor Pelayanan Kekayaan Negara dan Lelang Pematangsiantar. Jurnal SULTANIST. Vol.5, No.2.

Sekaran, Uma dan Roger Bougie. (2017). Metode Penelitian untuk Bisnis. Penerbit: Salemba 
Empat. Jakarta.

Wirawan. (2015). Manajemen Sumber Daya Manusia Indonesia. Jakarta: Raja Grafindo.

Wijayanti, Ratna. (2017). Pengaruh Iklim Organisasi, Etos Kerja dan Disiplin Kerja Terhadap Efektifitas Kinerja Organisasi Di Fakultas Ekonomi UNSIQ Wonosobo. Jurnal PPKM II.

Yusuf Muri. .(2014). Metode Penelitian: Kuantitatif, Kualitatif dan Penelitian Gabungan. Penerbit: Kencana. Jakarta.

Corresponding Author

e-mail: ririsna27@gmail.com 